\section{Science and the Architect}

Dr. R. E. Strading, director of Building Research under the Department of Scientific and Industrial Research, opened a materials gallery at the Liverpool School of Architecture in the Leverhulme Building of the University of Liverpool on November 29. In his address on the "Architect and Building Materials", Dr. Stradling said that the architect is required to create some form of protection, usually from the weather, which shall meet some intimate practical requirement of human existence, and in a progressive society moet it in such a way that beauty is added to everyday life. It seems almost self-evident that the knowledge of materials must be an ever-present mental background upon which the architect's mind must instinctively call if his artistic ability is to have reasonable scope. He must be equipped to meet his modern conditions, and there is an absence of adequate training on this side. In traditional English house design one usually finds a pitched roof with appreciable eaves, reasonable sills at the top and bottom of windows and doors, the walls constructed of brick or stone, or may be rough cast. No matter whether this type of design is artistically good or bad, such construction is usually thoroughly weatherproof if reasonably carried out in traditional materials. A typically modernist design consists of a box-like structure with flat roof, no weather projection over parapets, windows or doors; walls rendered in smooth Portland cement rendering. From inquiries received at the Building Research Station, it seems such structures are often anything but weather-proof. Before discarding old forms, it is essential to make sure that the now ones meet the essential protection requirements for which the building industry really stands. The real architect-artist is urgently re. quired with all the pioneering fire of which man is capable, but he must be properly trained to meet modern conditions. This can only be done by very much more intensive science work than is usual at present, for he must have a very real knowledge of the media in which he is to design.

\section{Minoan Survivals in Later Crete}

Some remarkable vistas in the history of European eivilisation are opened up in the report by Sir Arthur Evans of the discovery in October last of a temple of early Greek age in the island of Crete. The temple, which has been excavated by Dr. Marinatos, Ephor of Antiquities, is situated in the eastern part of the island on the hill site of the ancient town of Dreros, overlooking the lagoon of Spinalunga. It dates from the early part of the eighth century B.c., and is, therefore, the earliest known temple of the Greek age in the island. It differs, however, in proportions and character from other early Greek temples, and Sir Arthur in his communication in The Times of November 20 fully concurs in the view of Dr. Marinatos that it presents close affinities with pre-existing Minoan cults, such as might be preserved in an ancient Cretan tradition. He recalls that it was in this part of the island that the ancient Eteo-Cretan language survived down to historic times. Among the more noteworthy objects of the shrine, which was found in the characteristic Minoan position on the back-wall of the cella, are the cist-like altar filled with earth and quantities of goats' horns, reminding Dr. Marinatos of the altar erected by Theseus in honour of Ariadne, his Cretan consort, and bronze figures made of hammered plates, which had been fitted on to a wooden core, the first known examples of a technique to which reference is frequently made by Greek writers. Of these figures two, one male and one female, are evidence of the persistence of the 'mother and son' cult, which provides Sir Arthur with a link in a chain of evidence by which he traces the fundamental religious belief of the eastern Mediterranean from Knossos to Bethlehem.

\section{Explorations in New Guinea}

Additionar interest was attached by recent controversy to the account of his explorations in New Guinea which Mr. Michael Leahy gave to the Royal Geographical Society on November 21. It will be remembered that it has been suggested that Mr. J. G. Hides, who recently brought back some remarkable data relating to the unknown peoples he had encountered in the interior, had been in touch with some of the peoples of the Mount Hagen area dis. covered by Mr. Leahy, of whom an account has already reached England through Mr. E. W. P. Chinnery, the Government anthropologist of Papua. (See Nature, September 1, p. 328, August 17, 1935, p. 251 and August 24, p. 290.) The culture of the Mount Hagen people as deseribed by Mr. Leahy does indeed present certain features of similarity, such as the interest the people display in their gardens, which justify the comparison. Mr. Leahy's $\operatorname{cin} \theta-$ matograph film, especially in the war scenes-he was fortunate enough to obtain a record of an inter-tribal war in actual progress-gave a detailed picture of a remarkable, and in its environment unusual, culture. Especially interesting to archæologists was his report of the custom of eutting off a finger-joint at the death of a relative. This custom of finger mutilation is widespread among the more primitive peoples, and, as is well known, evidence of it is to be seen in the imprints of hands found among the prehistoric cave and rock paintings. The Mount Hagen peoples also practice preserving the skulls and some of the bones of their deceased relatives, which are placed in shrines along the road-side. It is to be noted that they are not cannibals, and expressed horror at the suggestion, although the practice exists among tribes nearer the coast. As a whole, Mr. Leahy's report has provided much interesting material for comparative study.

\section{Stone Age Culture in Colorado, U.S.A.}

Dr. Frank H. H. Roberts, JR., of the Bureau of American Ethnology, has resumed his investigation of the Lindenmeier site in Northern Colorado, U.S.A. (see Nature of October 5, p. 535), and for some weeks has been engaged in driving trenches in various directions near the habitation and factory site of Folsom man which he discovered in 1934. No less 